\title{
USO DE ÁGUA TRATADA POR OSMOSE REVERSA PARA A GERAÇÃO DE VAPOR EM INDÚSTRIA DE TABACO
}

\section{USE OF WATER PROCESSED BY REVERSE OSMOSIS FOR VAPOR GENERATION IN TOBACCO INDUSTRY}

\author{
Carlos Alberto Klimeck Gouvêa* E-mail: gouvea@sociesc.org.br \\ Ana Lúcia Berreta Hurtado*E-mail: ana.hurtado@sociesc.org.br \\ Rivelino Francisco Borzio** E-mail: rivelinoult@yahoo.com.br \\ Marchiel Augusto Folletto** E-mail: marchiel folletto@hotmail.com \\ *Sociedade Educacional de Santa Catarina,SOCIESC, Florianópolis, SC \\ ** Universal Leaf Tabacos Ltda, Santa Cruz do Sul, RS
}

Resumo: Este artigo apresenta um estudo decorrente do emprego da técnica de Osmose Reversa para o tratamento da água da caldeira para geração de vapor em uma usina de beneficiamento de fumos da região norte de Santa Catarina. O monitoramento foi realizado entre os anos de 2006 a 2008, apresentando os resultados referentes à melhoria da qualidade da água com ênfase aos ganhos ambientais e financeiros. A qualidade da água pode ser observada pela redução em $90 \%$ no teor de sílica e $100 \%$ na dureza, levando à diminuição da incrustação e da corrosão do sistema. Além disso, houve uma redução do volume de descargas, o que reduziu o consumo de água em aproximadamente $6.000 \mathrm{~m}^{3} / a n o$ e o consumo de produtos químicos utilizados na estação de tratamento de efluentes, com uma redução de $32,76 \mathrm{~m}^{3} /$ dia de efluentes para tratamento. A redução da energia com gás natural para aquecimento da água de reposição foi de quase $900.000 \mathrm{~m}^{3} / \mathrm{ano}$ $(19,45 \%)$, uma vez que houve aumento da eficiência de troca térmica, diminuindo, também, a emissão de $\mathrm{CO}_{2}$ na ordem de 1.215,65 t/ano. Por fim, com base nos resultados obtidos, infere-se que foi alcançada diminuição nos custos de produção como um todo.

Palavras-chave: Osmose reversa. Caldeira. Meio ambiente. Tratamento de água.

Abstract: This article presents a study due to the technical use of reverse osmosis to treat the boiler water for steam generation in a plant of tobacco processing in Santa Catarina, Brazil. The monitoring was conducted between the years 2006 to 2008, presenting the results concerning the improvement of water quality with emphasis on environmental and financial gains. Water quality can be observed by the reduction of $90 \%$ in silica content and $100 \%$ hardness, leading to a reduction of incrustation and corrosion of the system. Moreover, a reduction in the discharges water from the boiler volume reduced the water consumption by approximately $6,000 \mathrm{~m}^{3} /$ year and also the consumption of chemicals used in wastewater treatment plant, with a reduction of $32.76 \mathrm{~m}^{3} /$ day of effluents to treatment. The reducing of energy with natural gas for water heating replacement was almost $900,000 \mathrm{~m}^{3} /$ year $(19.45 \%)$, because of increased in heat exchange efficiency. The reducing in the $\mathrm{CO}_{2}$ emissions was in order of 1215,65 t/year. Finally, based on the achieved results obtained, can be possible to assume a reducing costs of production as a whole.

Keywords: Reverse osmosis. Boiler. Environment. Waste water treatment. 


\section{INTRODUÇÃO}

A preocupação com os recursos naturais renováveis é tema de grande importância em todo o mundo, estando a água como centro das preocupações. A água é objeto de diversos estudos há muitos anos, mesmo assim, não é possível exaurir todas as formas racionais de uso, redução de consumo e preservação dos mananciais. Portanto, casos de sucesso na gestão deste bem devem ser divulgados e incentivados.

Sabe-se que a utilização dos recursos hídricos tem criado diversas discussões, tanto devido à crescente demanda como pela preocupação com sua, quase certa, escassez futura. Segundo SILVA (2005), mais de um bilhão de pessoas vivem sem acesso a água potável de fontes confiáveis, mais de dois bilhões vivem em áreas com escassez de água e acredita-se que em 2025 esse número chegue a três bilhões e meio de pessoas. A escassez de água, que não ocorre somente em regiões áridas, pode ser caracterizada como um desencontro entre a água fornecida e a demanda de água. Tanto a poluição quanto a exploração dos aqüíferos e águas superficiais têm levado ao decréscimo da quantidade e qualidade das fontes de águas disponíveis em muitas regiões.

A água é um insumo essencial a vários processos industriais e, como normalmente não é encontrada pura na natureza, necessita de tratamento prévio para sua utilização. Muitas destas aplicações exigem que a água tenha uma qualidade superior à da água potável, requerendo um tratamento adicional para a redução de sólidos dissolvidos e suspensos, além de materiais orgânicos. Uma importante aplicação de água de alta pureza é na alimentação de caldeiras que geram vapor.

O presente trabalho expõe o estudo de caso da aplicação da Osmose Reversa para o tratamento da água em caldeira flamotubular a gás, em uma usina de beneficiamento de fumo situada na região norte de Santa Catarina, enfatizando os resultados técnicos e ambientais obtidos. Até então, entende-se como caso pioneiro neste segmento industrial. A empresa estudada é uma multinacional, sendo a maior usina de beneficiamento do Estado de Santa Catarina, com sua matriz mundial nos Estados Unidos. 


\section{OBJETIVO}

O objetivo deste trabalho é avaliar os ganhos técnicos e ambientais obtidos com a implantação do sistema de ultra purificação da água através da utilização de um equipamento de Osmose Reversa. Especificamente, através do uso de um equipamento de Osmose Reversa serão quantificados os seguintes benefícios: (i) melhoria da qualidade da água de reposição da caldeira; (ii) elevação no ciclo de concentração da caldeira; (iii) ganhos técnicos; (iv) redução no volume de purgas; (v) redução do consumo de água e geração de efluentes; (vi) redução no consumo de combustível e emissão de $\mathrm{CO}_{2}$; (vii) ganhos financeiros e (viii) ganhos ambientais.

\section{JUSTIFICATIVA}

A indústria fumageira consome grandes quantidades de água em suas operações de beneficiamento do fumo, especialmente na produção de vapor. $O$ vapor é, principalmente, utilizado no condicionamento da folha do fumo, onde o calor e a umidade tornam o produto macio e flexível. Esta característica garante as condições ideais de processamento e tem como objetivo evitar que a matéria-prima seja desperdiçada, que haja desgaste das máquinas, perdas financeiras e, principalmente, que mantenha a integridade e qualidade do produto. $O$ vapor também é uma importante fonte de energia para o aquecimento dos trocadores de calor (secadores), que são os equipamentos utilizados para reduzir a umidade do produto a patamares que garantam a sua conservação.

Normalmente, as caldeiras são abastecidas com água da rede ou de poço artesiano após abrandamento com resinas de troca iônica. Mesmo assim, a quantidade de sais dissolvidos concentra-se consideravelmente em função da grande taxa de evaporação. Os sais concentrados levam a problemas de entupimento dos bicos sopradores de vapor (incrustação), demandando manutenção constante.

Incrustação é um fenômeno comentado e estudado há muitos anos, com explicações demasiado técnicas e outras vezes com linguagem coloquial. Pode-se explicar o fenômeno com base na qualidade da água, veículo considerado popularmente como um solvente universal, o qual sempre carrega íons dissolvidos e 
sais dispersos (TORREIRA, 1995). Logo, todos os íons dissolvidos e sais dispersos têm possibilidade de se acumularem nas tubulações e equipamentos, sendo este acúmulo intensificado quando a água é evaporada nos sistemas que operam em temperaturas elevadas.

Os sistemas de refrigeração baseiam-se na remoção da energia térmica pela evaporação da água. Contudo, os íons presentes na água permanecem na fase líquida, dissolvidos quando ionizados ou dispersos quando no estado sólido, ficando o meio cada vez mais concentrado na medida em que a água evapora. Este fenômeno de aumento da concentração de sais no meio aquoso promove incrustações e, também, corrosão. Evidentemente que a velocidade da incrustação e da corrosão dependem de outros fatores como temperatura, $\mathrm{pH}$, tipos de sais presentes, oxigenação do meio, tipo de metal a ser atacado etc.

A incrustação nos equipamentos e tubulações diminui a eficiência da troca térmica e obstrui o sistema, provocando paradas e, muitas vezes, danos nos equipamentos. Quando a incrustação está presente no sistema, ocasionando a diminuição na eficiência da troca térmica, ocorre um aumento no consumo de energia para compensar esta deficiência, implicando em um aumento de combustível. Entretanto, este não é o único problema, pois um aumento na temperatura da caldeira propicia a fadiga dos materiais, formando locais com aeração diferenciada, acelerando o processo de corrosão. Ao final, aumenta-se o risco de explosão das caldeiras pelo somatório dos problemas mencionados em função das características da água.

Na prática, realiza-se o processo de purga, que serve para remoção da água interna, mais concentrada em sais, além da retirada de condensado do sistema, o qual rouba energia do mesmo. Sabe-se que a cada purga é retirada água em alta temperatura, com a perda da respectiva energia nela contida e, que a nova água reposta no sistema, irá consumir energia para atingir a temperatura de processo.

Estes são os motivos pelos quais as águas de caldeiras são analisadas quimicamente, visando orientar os operadores sobre as necessidades de purga, abrandamento, regulagem de $\mathrm{pH}$ e outros meios para adequá-la às necessidades do processo. 
A empresa em estudo possui diversos problemas com o sistema de geração de vapor, que se dão em função das características do equipamento e da qualidade da água a ser tratada, conforme segue:

1) Formação de incrustações nas tubulações e no equipamentos de troca térmica da caldeira devido à elevada temperatura de operação da caldeira. Os minerais, até então mantidos sob forma solubilizada na água de alimentação e de reposição, oferecem tendência à deposição sob a superfície de troca térmica da caldeira, consequentemente, apresentando incrustações de difícil remoção.

2) Elevado volume de descargas de fundo (a cada 10 minutos), implicando em consumo excessivo de água. As partículas sólidas em suspensão na água de alimentação podem se depositar formando uma camada de lama corrosiva no fundo da caldeira, o que reduz a vida útil desse equipamento. Além disso, as impurezas formam incrustações nas paredes internas, o que também dificulta a troca térmica. Por isso, as descargas de fundo são necessárias para a eliminação da lama precipitada, evitando assim, as corrosões e incrustações na rede de distribuição, na superfície de troca térmica e na própria caldeira.

3) Aumento do volume de efluentes, visto que toda a água eliminada pelas descargas de fundo são direcionadas para a Estação de Tratamento de Efluentes da empresa.

4) Elevação nos custos de operação, pois um elevado volume de reposição de água na caldeira tem como conseqüência um grande aumento nos custos operacionais, uma vez que gera aumento no consumo de combustível (gás natural), aumento no consumo de energia no bombeamento para captação de água e aumento no consumo de produtos químicos para o tratamento da água de alimentação/reposição. Um elevado volume de efluente gerado pelo grande número de descargas, causa, consequentemente, um aumento no custo com tratamento deste efluente.

5) Elevação da temperatura dos efluentes da ETE devido ao aumento das descargas de fundo da caldeira direcionados para a Estação de Tratamento de Efluentes. Esta elevação da temperatura dos efluentes causa uma diminuição na atividade dos microorganismos presentes no tanque de aeração e, até mesmo, causa a morte de muitos. 
O impacto ambiental resultante do uso de água tratada somente por resina de troca iônica na caldeira era grande, pois exigia consumo de recursos naturais como a água e gás natural. O grande consumo e desperdício de água gerava a necessidade de um maior consumo de combustível para manter a produção de vapor e, consequentemente, um aumento nas emissões de $\mathrm{CO}_{2}$. Todos os problemas anteriormente citados ainda traziam, como conseqüência, o comprometimento da produtividade da empresa. Em várias situações a produtividade teve que ser limitada à produção de vapor, insuficiente para a demanda do processo ou pela limitação da captação da água.

Em função deste problema a empresa viu a necessidade de buscar outro processo como coadjuvante no tratamento da água (já tratada por resina de troca iônica). Como única opção para obtenção de água ultra pura para completa eliminação de traços de elementos em água já tratada por resina de troca iônica, é o uso de membranas ultrafiltrantes, em particular a Osmose Reversa, processo aplicado em indústria de fabricação de laticínios, medicamentos e alimentos (SKELTON, 2000, BRIÃO, 2007, VOURCH, 2007, BRUM, 2009).

A motivação da busca da solução do problema não foi somente em função das questões técnicas e econômicas, mas também ambiental, pois a empresa possui como estratégia operacional a otimização do uso dos recursos naturais, no consumo de água, de energia elétrica e prevenção da poluição através da redução no volume de tratamento dos efluentes industriais e do controle de emissões atmosféricas, metas da norma implantada ISO 14.000.

\section{OSMOSE REVERSA}

Os processos por Osmose Reversa datam seu início em meados da metade do século 20, na qual houve o surgimento de pesquisas pela busca de soluções para o tratamento da água do mar para torná-la potável. Após o fim da II Guerra Mundial, a população da Califórnia teve um crescimento rápido e a região semi-árida estava enfrentando problemas com o abastecimento de água potável. Durante este período, a "conversão da água" de solução salina foi motivo de pesquisa de alta prioridade nos Estados Unidos e, especialmente, na Universidade da Califórnia. Em 1952, o Ministério do Interior criou o Escritório de Água Salina, que lançou uma abrangente 
pesquisa no desenvolvimento da dessalinização. Em 1954, um equipamento foi construído para a verificação experimental dos estudos, equipamento este chamado de "Conversor para o princípio da osmose" (GLARER, 1998, BJERKE, 2002).

A Osmose Reversa, objeto de estudo do presente trabalho, também é conhecida na literatura técnica como Osmose Inversa (RAMOS, 2008). O processo de osmose é aquele no qual a água passa do meio mais diluído (meio hipotônico) para o meio mais concentrado (meio hipertônico), a fim de equilibrar as concentrações. O processo só é possível quando as duas soluções estão separadas por uma membrana com porosidade suficiente para que passe somente água e nada mais.

O fenômeno da osmose ocorre naturalmente em função da chamada "pressão osmótica", a qual empurra a água do meio diluído para o meio mais concentrado. A explicação é simples, como somente a água passa pela membrana semipermeável, o meio mais diluído (menos concentrado) sempre tem mais água para passar para o meio mais concentrado, do que o inverso. Assim, o processo é dinâmico até que seja atingido o equilíbrio, ou seja, a velocidade de migração da água seja igual para os dois lados da membrana semipermeável.

Se forem colocadas duas soluções de concentrações diferentes separadas por uma membrana semipermeável, a velocidade de migração da água do meio hipotônico (menos concentrado) para o meio hipertônico (mais concentrado) fará com que haja um desnível entre as soluções, desnível este conhecido como pressão osmótica (figura 1).

A Osmose Reversa é aquela em que a água está passando do meio mais concentrado para o mais diluído, ou seja, está realizando um caminho inverso àquele imposto pela pressão osmótica. Para tanto, é necessário fornecer energia ao sistema e esta energia é dada pela pressão hidráulica artificial, imposta ao sistema. Transportar água do meio mais concentrado para o menos concentrado equivale a diminuir ainda mais a concentração do soluto presente no meio aquoso. Com base neste fato, é possível utilizar o processo de osmose reversa para purificar ainda mais as soluções. 
Figura 1- Princípio da Osmose Reversa

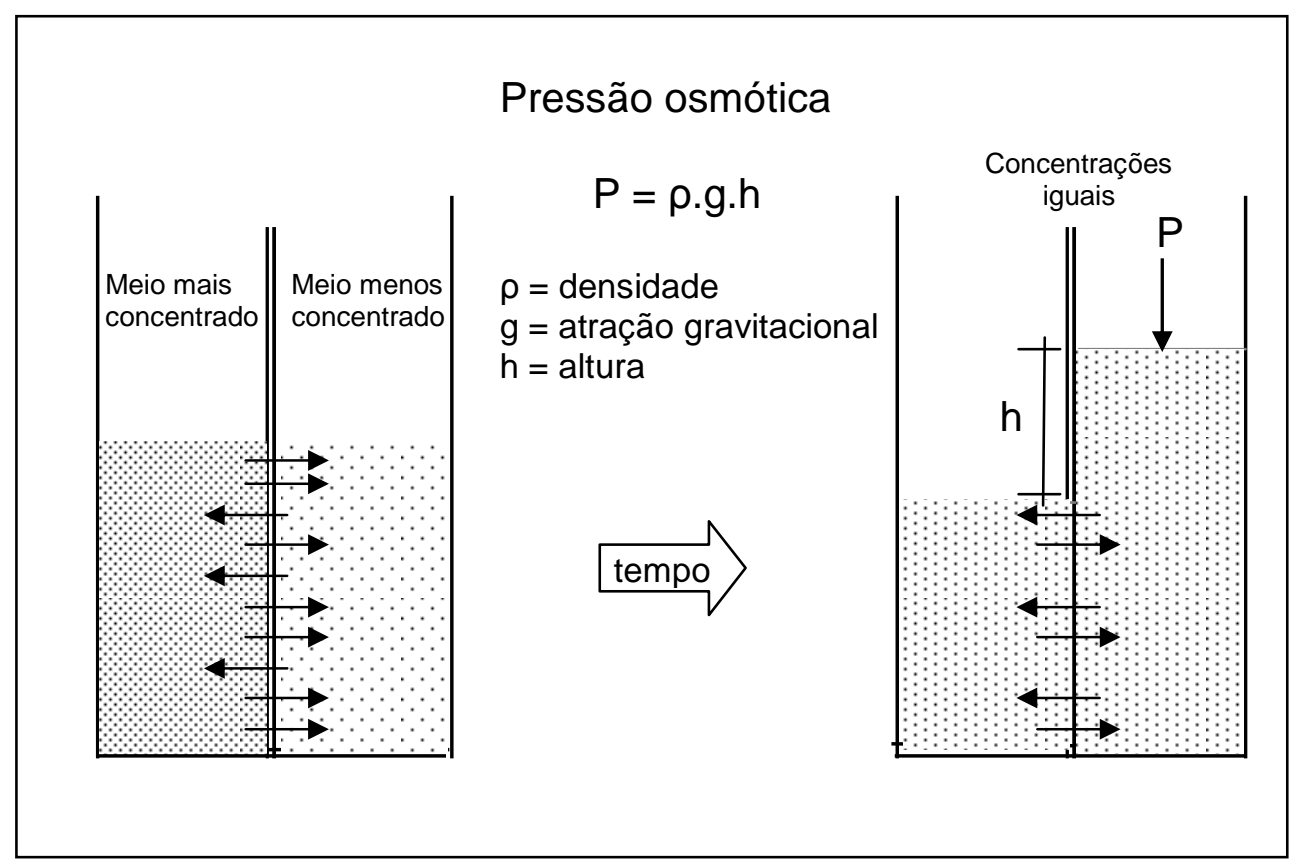

Fonte: Os autores

O processo de tratamento de água por osmose reversa consiste, então, em fazer passar de forma forçada água limpa através de uma membrana semipermeável, a qual só permitirá passar água e não as demais substâncias e elementos que estejam presentes no meio, tornando a água mais pura.

O tratamento da água por Osmose Reversa é bastante simples e de baixo custo operacional, às vezes necessitando apenas de uma bomba pressurizadora e que o sistema seja alimentado com água de qualidade, caso contrário, haverá rápida obstrução da membrana filtrante. Logo, mesmo que o sistema seja alimentado por água de qualidade haverá ao longo de operação uma inevitável obstrução da membrana filtrante. Por este motivo, o processo depende de retrolavagens periódicas para a desobstrução da membrana.

Em um moderno equipamento de Osmose Reversa, são usadas fibras com microporosidade como a membrana semipermeável. A maior usina de dessalinização do mundo está localizada em Jubail, Arábia Saudita. Essa usina fornece $50 \%$ da água potável daquele país usando Osmose Reversa para dessalinizar a água do mar do Golfo Pérsico (MILLER, 2003). Tais usinas estão se tornando cada vez mais comuns nos Estados Unidos. Em 1992, por exemplo, a cidade de Santa Bárbara, Califórnia, inaugurou uma usina de Osmose Reversa que 
pode produzir 30 bilhões de litros de água potável por dia. Dessanilizadores de Osmose Reversa de operação manual em pequena escala estão agora também disponíveis para uso em acampamentos e viagens pelo mar (BROWN, LEMAY E BURSTEN, 2005).

O processo de dessalinização da água do mar teve seu custo reduzido ao longo do tempo e, atualmente, o preço da água dessalinizada está estimado em 1,50 US $\$ / \mathrm{m}^{3}$. Considerando que, hoje em dia, certas unidades de tratamento produzem água com um custo total de cerca de $0,50 \mathrm{US} \$ / \mathrm{m}^{3}$, ou seja, valor não relativamente próximo ao da água tratada por osmose reversa (MOLINA, 2009).

\section{METODOLOGIA}

A metodologia foi desenvolvida a partir dos dados obtidos das análises químicas da água proveniente dos poços artesianos. Esses resultados analíticos demonstraram que a osmose reversa é a única alternativa para melhoria da qualidade de uma água já tratada por resina de troca iônica, visto que é um póstratamento. Portanto, o uso da osmose reversa constituiu como única opção para o problema em questão, considerando que é a alternativa capaz de elevar uma água purificada por resina de troca catiônica em água ultra pura.

Para a demanda de geração de vapor, faz-se necessário identificar as características da empresa estudada, quanto ao tipo de caldeira, no caso flamotubular, marca Sermatec, fabricação 2005, capacidade de geração de nominal vapor de $25 \mathrm{t} / \mathrm{h}$ com uma pressão máxima de trabalho de $11 \mathrm{kgf} / \mathrm{cm}^{2}$.

A água que a empresa utiliza tem como origem poços semi artesianos, em um total de seis, com capacidade de produzir até $20 \mathrm{~m}^{3}$ de água por hora. $\mathrm{O}$ armazenamento da água é feito em quatro tanques, juntos totalizando $500 \mathrm{~m}^{3} \mathrm{de}$ capacidade.

O equipamento de osmose reversa com a capacidade necessária para o caso é produzido pela GE Water \& Process Technologies e as análises químicas da água foram feitas através de uma parceria com a empresa fabricante do equipamento.

Por fim, foi realizada a medição da quantidade consumida de água, antes e depois da implantação do processo, o volume de água de purga descartado, o consumo de produtos químicos na ETE, o consumo de gás para aquecimento da 
caldeira na temperatura de processo, o consumo de energia elétrica das bombas de sucção dos poços artesianos, além das despesas com paradas e manutenção em função de entupimento dos bicos sopradores.

\section{RESULTADOS E DISCUSSÕES}

Inicialmente, de forma a caracterizar a qualidade da água de alimentação e de reposição da caldeira, foram feitas análises químicas e físico-químicas, as quais deram suporte para o sistema de tratamento de água que poderia ser implantado (Tabelas 1 e 2).

Tabela 1- Características da água tratada por resina de troca iônica usada na alimentação da caldeira

\begin{tabular}{llll|l}
\hline Parâmetro & Unidade & Mínimo & Máximo & Média \\
\hline Sílica Solúvel & $\mathrm{ppm}$ & 23,4 & 41,0 & $\mathbf{3 4 , 2}$ \\
Condutividade & $\square \mathrm{s} / \mathrm{cm}^{2}$ & 93,0 & 243,0 & $\mathbf{1 9 4 , 7}$ \\
Cloretos & $\mathrm{ppm}$ & 6,0 & 11,0 & $\mathbf{7 , 6}$ \\
Ferro Total & $\mathrm{ppm}$ & 0,2 & 0,4 & $\mathbf{0 , 3}$ \\
Dureza Total & $\mathrm{ppm}$ & 0,0 & 90,0 & $\mathbf{6 , 4}$ \\
\hline
\end{tabular}

Fonte: Relatório dos Resultados Analíticos dos Sistemas de Resfriamento e Geração de Vapor-GE , 2006.

Tabela 2- Características da água de recirculação da caldeira de vapor

\begin{tabular}{llll|l}
\hline Parâmetro & Unidade & Mínimo & Máximo & Média \\
\hline Sílica & $\mathrm{ppm}$ & 15,5 & 45,0 & $\mathbf{2 1 , 4}$ \\
Condutividade & $\square \mathrm{s} / \mathrm{cm}^{2}$ & 114,0 & 1119,0 & $\mathbf{2 4 8 , 0}$ \\
Cloretos & $\mathrm{ppm}$ & 3,0 & 92,0 & $\mathbf{2 0 , 3}$ \\
Ferro Total & $\mathrm{ppm}$ & 0,1 & 1,9 & $\mathbf{0 , 5}$ \\
Dureza Total & $\mathrm{ppm}$ & 0,0 & 42,0 & $\mathbf{3 , 1}$
\end{tabular}

Fonte: Relatório dos Resultados Analíticos dos Sistemas de Resfriamento e Geração de Vapor-GE , 2006.

O processo desde a captação de água até a geração de vapor, incluindo o sistema de Osmose Reversa está apresentado na figura 2. 
Figura 2 - Processo de captação e tratamento de água e reservação utilizado na empresa

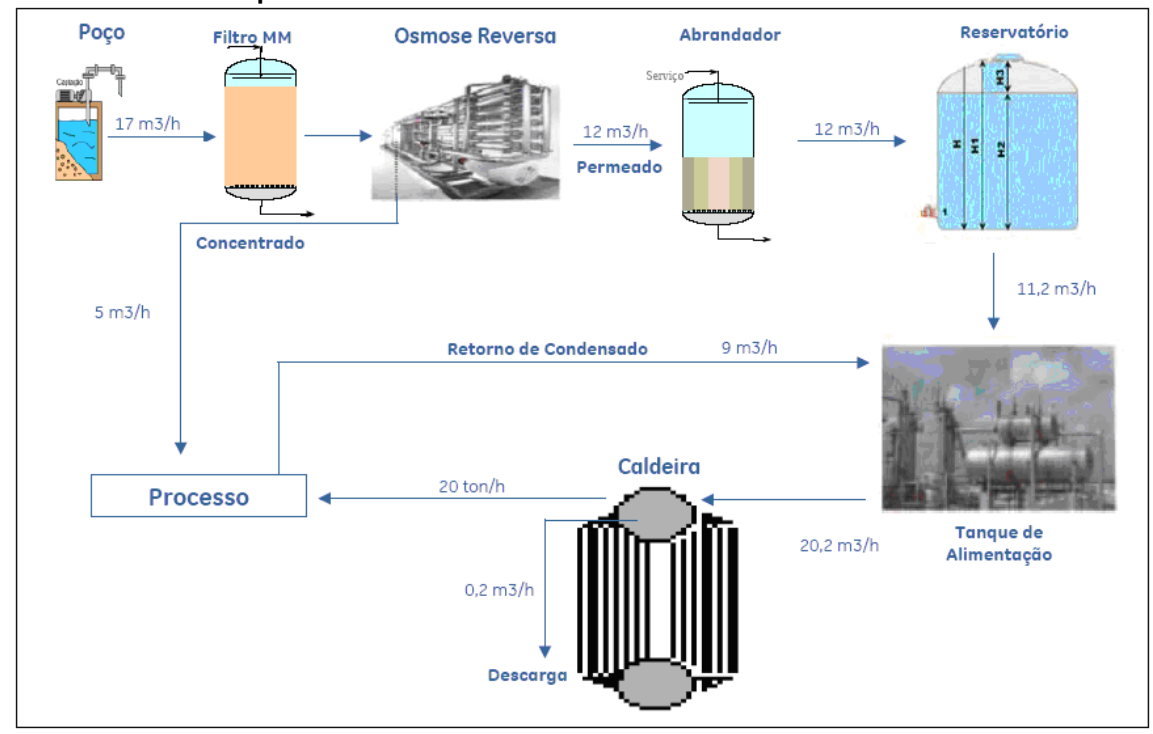

Fonte: Empresa

É possível verificar na figura 2 o volume de água consumido e a perda de $0,2 \mathrm{~m}^{3} / \mathrm{h}$ na descarga da caldeira.

A instalação do sistema de Osmose Reversa ocorreu em meados de 2007, sendo que durante aquele ano o funcionamento estava em fase de teste, objetivando os ajustes e adaptações necessárias. A partir de 2008 o sistema entrou em funcionamento otimizado.

Após a utilização do sistema de Osmose Reversa conseguiu-se uma grande melhoria nas características da qualidade da água, que teve reduzida a dureza e a concentração de minerais dissolvidos, conforme apresentado nas Tabelas 3 e 4 .

Tabela 3 - Características da água após o sistema de osmose reversa

\begin{tabular}{llll|l}
\hline Parâmetro & Unidade & Mínimo & Máximo & Média \\
\hline Sílica Solúvel & $\mathrm{ppm}$ & 0,0 & 0,5 & $\mathbf{0 , 3}$ \\
Condutividade & $\square \mathrm{s} / \mathrm{cm}^{2}$ & 7,3 & 12,7 & $\mathbf{1 0 , 9}$ \\
Cloretos & $\mathrm{ppm}$ & 1,4 & 4,2 & $\mathbf{2 , 2}$ \\
Ferro Total & $\mathrm{ppm}$ & 0,0 & 0,1 & $\mathbf{0 , 0}$ \\
Dureza Total & $\mathrm{ppm}$ & 0,0 & 0,0 & $\mathbf{0 , 0}$ \\
\hline
\end{tabular}

Fonte: Relatório dos Resultados Analíticos dos Sistemas de Resfriamento e Geração de Vapor - GE , 2008. 
Tabela 4 - Características da água de recirculação na caldeira após a osmose reversa

\begin{tabular}{lllll}
\hline Parâmetro & Unidade & Mínimo & Média & Máximo \\
\hline Sílica & $\mathrm{ppm}$ & 0,11 & $\mathbf{0 , 2 0}$ & 0,34 \\
Condutividade & $\square \mathrm{s} / \mathrm{cm}^{2}$ & 70,70 & $\mathbf{8 9 , 0 0}$ & 147,00 \\
Cloretos & $\mathrm{ppm}$ & 0,00 & $\mathbf{0 , 0 0}$ & 0,00 \\
Ferro Total & $\mathrm{ppm}$ & 0,05 & $\mathbf{0 , 1 0}$ & 0,16 \\
Dureza Total & $\mathrm{ppm}$ & 0,00 & $\mathbf{0 , 0 0}$ & 0,00
\end{tabular}

Fonte: Relatório dos Resultados Analíticos dos Sistemas de Resfriamento e Geração de Vapor - GE , 2008.

Comparando os resultados das análises apresentados nas Tabelas 1 e 2 com os resultados das Tabelas 3 e 4, verifica-se que houve uma redução de $90 \%$ no teor de sílica e de $100 \%$ na dureza. Este ganho é, sem dúvidas, muito importante para a solução do problema de entupimento dos bicos injetores de vapor, principal motivo das paradas para manutenção.

Com a água de melhor qualidade, foi possível reduzir, significativamente, o volume de descargas. Assim, conseguiu-se uma redução de 1,450 para apenas $0,085 \mathrm{~m}^{3} / \mathrm{h}$ de água na descarga de vapor, ou seja, uma economia de $1,365 \mathrm{~m}^{3} / \mathrm{h}$ de água, equivalente a aproximadamente $8 \%$ do total da água captada para o sistema de geração de vapor. O valor anual de água economizada é bastante expressivo, um total de quase 6 milhões de toneladas de água. Os resultados alcançados com a redução das descargas estão apresentados na Tabela 5.

Tabela 5 - Redução no volume de água em descargas

\begin{tabular}{lccc}
\hline \multicolumn{1}{c}{ Descarga } & $\begin{array}{c}\text { Volume } \\
\left(\mathrm{m}^{3} / \text { hora }\right)\end{array}$ & $\begin{array}{c}\text { Volume } \\
\left(\mathrm{m}^{3} / \mathrm{dia}\right)\end{array}$ & $\begin{array}{c}\text { Volume } \\
\left(\mathrm{m}^{3} / \mathbf{a n o}\right)\end{array}$ \\
\hline $\begin{array}{l}\text { Antes da osmose } \\
\text { reversa }\end{array}$ & 1,450 & 34,800 & 6.264 .000 \\
$\begin{array}{l}\text { Depois da osmose } \\
\text { reversa }\end{array}$ & 0,085 & 2,040 & 367.200 \\
\begin{tabular}{l} 
Redução \\
\hline
\end{tabular} & 1,365 & 32.760 & $\mathbf{5 . 8 9 6 . 8 0 0}$ \\
\hline
\end{tabular}

Fonte: Empresa (2008)

Com a redução do volume de descargas da caldeira, conseqüentemente, houve uma redução significativa no consumo de água gerando, assim, uma redução 
com os custos de energia para captação de água. A significativa redução do volume de descargas de fundo da caldeira reduziu também o volume de água de realimentação da caldeira, o que evitou as perdas de calor. Também proporcionou um melhor rendimento térmico em função da redução das incrustações, promovendo uma redução de $7,53 \mathrm{~m}^{3}$ de gás natural por tonelada de fumo processado (Tabela 6).

Tabela 6 - Consumo de gás natural por tonelada de fumo processado e respectiva geração de $\mathrm{CO}_{2}$, antes e depois da implantação do sistema de osmose reversa

\begin{tabular}{|c|c|c|c|c|c|c|}
\hline Ano & $\begin{array}{l}\text { Consumo } \\
\text { de gás } \\
\text { natural no } \\
\text { ano }\left(\mathrm{m}^{3}\right)\end{array}$ & $\begin{array}{l}\text { Redução } \\
\text { de } \\
\text { consumo } \\
\text { de gás } \\
\left(\mathrm{m}^{3} / \text { ano }\right)\end{array}$ & $\begin{array}{l}\text { Consumo } \\
\text { ( } \mathrm{m}^{3} \text { gás / } \\
\text { tonelada } \\
\text { de fumo) }\end{array}$ & $\begin{array}{c}\text { Redução de } \\
\text { gás/tonelada } \\
\text { de folha } \\
\left(\mathrm{m}^{3} / \mathrm{t}\right)\end{array}$ & $\begin{array}{c}\text { Redução } \\
(\%)\end{array}$ & $\begin{array}{c}\text { Redução de } \\
\text { emissão de } \\
\mathrm{CO}_{2} \text { (t/ano) } \\
(1,734 \mathrm{t} \text { de } \\
\mathrm{CO}_{2} \text { por m }{ }^{3} \\
\text { de gás) }\end{array}$ \\
\hline $\begin{array}{c}2006 \\
\text { (sem osmose } \\
\text { reversa) }\end{array}$ & 3.871 .000 & - & 38,71 & - & - & $x_{2}$ \\
\hline $\begin{array}{c}2007 \\
\text { (com osmose } \\
\text { reversa) }\end{array}$ & 3.529 .680 & 341.320 & 36,96 & 1,75 & 4,52 & 289,79 \\
\hline $\begin{array}{c}2008 \\
\begin{array}{c}\text { (com osmose } \\
\text { reversa) }\end{array}\end{array}$ & 2.974 .042 & 896.958 & 31,18 & 7,53 & 19,45 & $1.215,65$ \\
\hline
\end{tabular}

Além da economia de gás natural, outro ganho ambiental que pode ser observado com os resultados da Tabela 6 é a redução nas emissões de dióxido de carbono para o meio ambiente. Com a redução alcançada no consumo de combustível, obteve-se uma redução de 1.215,65 t/ano na emissão de $\mathrm{CO}_{2}$.

Considerando que a empresa consumia $3.871 .000 \mathrm{~m}^{3}\left(36,96 \mathrm{~m}^{3}\right.$ de gás/t de folha) de gás por ano (2007) e passou a ter um consumo de $2.974 .042 \mathrm{~m}^{3}\left(31,18 \mathrm{~m}^{3}\right.$ de gás/t de folha), isto significou uma economia de $R \$ 639.228,25$, para um custo de $\mathrm{R} \$ 0,89$ o metro cúbico do gás.

Houve uma redução de $32,76 \mathrm{~m}^{3} /$ dia de efluentes para tratamento (Tabela 5). Considerando um custo médio na empresa de $R \$ 3,50 / \mathrm{m}^{3}$ de efluente tratado, resultou em uma economia de $\mathrm{R} \$ 20.638,80$ por ano. Por fim, também é importante ressaltar que os custos de hora-homem na manutenção e perda por produção não foram aqui considerados, contudo, sabe-se que são custos expressivos. 


\section{CONCLUSÃO}

O resultado da análise da água antes e após a implantação do sistema de osmose reversa mostrou melhoras na sua qualidade, principalmente no que se refere aos teores de sílica e dureza. $O$ estudo mostrou que com uma água mais pura foi possível reduzir o número de purgas e permitir que a água ficasse em recirculação por mais tempo. Permitiu também uma redução na formação das indesejáveis incrustações, assim como a redução no processo de corrosão do sistema. Apesar de não terem sido quantificadas as horas de manutenção pela ausência de histórico formal antes da implantação do sistema, a redução foi real segundo o departamento específico. O consumo de água apresentou redução de $5.896 .800 \mathrm{~m}^{3}$ por ano. Como conseqüência, houve diminuição no volume de água a ser tratada na ETE pela redução de purgas, com direta redução de produtos químicos para este tratamento, apesar de não quantificado. Quanto ao consumo de metano, houve redução de quase $900.000 \mathrm{~m}^{3}$ por ano $\left(896.958 \mathrm{~m}^{3}\right)$, o equivalente a 19,45\% a menos de gás queimado para aquecer a água de reposição do sistema e correspondente redução 1.215,65t/ano de $\mathrm{CO}_{2}$ que deixaram de serem geradas. Por falta de histórico no consumo de energia elétrica para o bombeamento de água dos poços semi artesianos, não pode ser comprovado o quanto houve de redução de energia para este fim, além do bombeamento da água na ETE. Os ganhos financeiros podem ser considerados como ganhos ambientais indiretos, pois estimulam boas práticas de produção. Assim, houve redução da hora máquina parada e no custo com mão-de-obra em manutenção e operações, os quais não estão voltados diretamente para o processo produtivo, podendo ser considerados todos como ganhos provenientes da implantação do sistema comentado.

\section{REFERÊNCIAS}

BJERKE, B. Membrane technology and costs: the state of art. Desalination, Amsterdan: Elsevier Science Publisher B.V, v. 35, p. 375 - 382, 2002.

BRIÃO, Vandré Barbosa. Processos de separação por membranas para reuso de efluentes de laticínios. Maringá. (Tese de Doutorado apresentada ao Programa de Pós Graduação em Engenharia Química da Universidade Estadual de Maringá), 2007. 
BROWN, Theodore L.; LEMAY, H. Eugene; BURSTEN, Bruce E.. Química a ciência central. 9. ed. Sao Paulo: Editora Prentice Hall, 2005.

BRUM, L. F. W., SANTOS JÚNIOR, L. C. O., BENEDETTIC, S.. Reaproveitamento de água de processo e resíduos da indústria de laticínios, International Worshop Advanced in Cleaner Production, 2009.

GLARER, Julius. The early history of reverse osmosis membrane. Revista Desalination, Los Angeles, p.297-309, 7 June 1998.

MILLER, J. E. Review of water resources and desalination technologies SANDIA, 2003 (acesso www.sandia.gov/water/docs/MillerSAND2003 0800).

MOLINA, Verónica García; CASAÑAS, Antonio. Reverse osmosis, a key technology in combating water scarcity in Spain. Revista Desalination, Las Palmas de Gran Canaria - Spain, p.950-955, 13 Oct. 2009.

RAMOS, Gabriela Marques Dos. Fibras ocas compostas para osmose inversa e nanofiltração baseada em poli (álcool vinilico) com resistência a agentes oxidantes e incrustações orgânicas. $208 \mathrm{f}$. Tese (Doutorado) - Curso de Engenharia Química, Universidade Federal do Rio de Janeiro, Rio de Janeiro, 2008.

SILVA, Maurício Kipper da. Estudo da influência das monocloraminas sobre as membranas de poliamida na osmose inversa. $137 \mathrm{f}$. Dissertação (Mestrado) Curso de Engenharia Química, Universidade Federal do Rio Grande do Sul, Porto Alegre, 2005.

SKELTON, Robert. Membranes in food processing: filtration and separation. Amsterdan: Elsevier Science, 2000, v. 37, n. 3 p. 28 - 30, 2000.

TORREIRA, Raul Peragallo. Geradores de vapor. 1.ed. São Paulo: Editora Libris, 1995.

VOURCH, Mickael; BALANNEC, Béatrice; BERNARD, Chaufer; GÉRARD, Dorange. Treatment of dairy industry wastewater by reverse osmosis for water reuse. Revista Desalination, Rennes: Elsevier Science Publisher B.V, v. 219, p. 190 - 202, 2007.

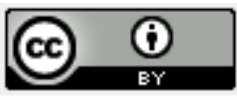

Artigo recebido em 21/02/2011 e aceito para publicação em 28/03/2012. 